\title{
ANÁLISE DE VIABILIDADE: IMPLEMENTAÇÃO DE UM NOVO EMPREENDIMENTO EM UMA EMPRESA DE TRANSPORTE UNIVERSITÁRIO E TURISMO DE TOLEDO
}

\author{
FEASIBILITY ANALYSIS: IMPLEMENTATION OF A NEW ENTERPRISE IN A UNIVERSITY \\ AND TOURISM TRANSPORT COMPANY IN TOLEDO CITY
}

\author{
Recebido em 19.12.2019 Aprovado em 09.03.2020 \\ Avaliado pelo sistema double blind review \\ DOI: https://doi.org/10.32888/cge.v8i1.40143
}

\begin{abstract}
Augusto Henrique Vieira
augusto-viera@hotmail.com

Curso de Administração/Universidade Estadual do Oeste do Paraná - Marechal Cândido Rondo/Paraná, Brasil https://orcid.org/0000-0002-0269-4259
\end{abstract}

\section{Germano de Paula}

germano5043@hotmail.com

Curso de Administração/Universidade Estadual do Oeste do Paraná - Marechal Cândido Rondo/Paraná, Brasil https://orcid.org/0000-0002-7239-5983

\section{Silvana Anita Walter}

silvanaanita.walter@gmail.com

Curso de Administração/Universidade Estadual do Oeste do Paraná - Marechal Cândido Rondo/Paraná, Brasil https://orcid.org/0000-0003-1684-5465

\section{Resumo}

Este estudo teve como objetivo analisar a viabilidade econômico-financeira de um projeto de abertura de uma nova linha de transporte universitário do município de Toledo para Marechal Cândido Rondon-PR. Empregouse uma abordagem quantitativa; descritiva, por intermédio de análise documental. Com ajuda dos indicadores de viabilidade e modelos de planos de negócios, realizou-se a análise do futuro empreendimento. Constatou-se a viabilidade do negócio e a importância de sua elaboração antes da execução do projeto, possibilitando ao gestor reduzir os riscos associados as suas incertezas e expectativas, além de proporcionar uma visão do funcionamento do futuro empreendimento.

Palavras-chave: Análise de viabilidade. Transporte universitário. Plano de negócios.

\begin{abstract}
This study aimed to analyze the economic and financial feasibility of a project to open a new university transportation line between the cities of Toledo and Marechal Cândido Rondon-PR. A quantitative approach was used; descriptive, through documentary analysis. With the help of feasibility indicators and business plan models, an analysis of the future undertaking was carried out. It was verified the viability of the business and the importance of its preparation before the execution of the project, allowing the manager to reduce the risks associated with his uncertainties and expectations, in addition to providing a vision of the functioning of the future enterprise.
\end{abstract}

Keywords: Feasibility analysis. University transportation. Business plan. 


\section{Introdução}

O setor de serviços está em expansão e, em todo o mundo, há uma crescente prevalência de economias voltadas a esse campo (ZEITHAML; BITNER; GREMLER, 2014). No Brasil, este setor vem apresentando crescimento econômico, o que resulta na expansão da economia, afetando diretamente em resultados financeiros expressivos para o país (NERI, 2015).

A competição entre as empresas aumenta de forma drástica ao passar do tempo e são poucos os setores em que a competição não interferiu diretamente na estabilidade das empresas no mercado (PORTER, 1999).

Em uma pesquisa realizada pelo Serviço Brasileiro de Apoio às Micro e Pequenas Empresas (SEBRAE) e a Fundação Universitária de Brasília, durante o período de 2000/2002, constatou-se que aproximadamente $60 \%$ das empresas brasileiras de pequeno e médio porte acabam falindo antes mesmo de completar 5 anos e um dos principais motivos para isso acontecer se deve aos problemas com a gestão financeira.

A realização de estudos que buscam conhecimentos sobre fatores que influenciam o sucesso empresarial é de grande importância, contudo, Longenecker, Moore e Petty (1997, p. 161) afirmam que os empreendedores tendem a negligenciar o período de planejamento de um novo empreendimento.

O plano de negócios é uma grande ferramenta utilizada, tanto para iniciar um negócio, quanto para ampliar um empreendimento, diminuindo a possibilidade de riscos durante a execução do projeto e permitindo o gestor identificar os seus erros antes mesmo deles realmente acontecerem (SEBRAE, 2019).

Muitas empresas tendem a fechar as portas por não realizarem um estudo de viabilidade antes da execução do projeto. Este serve para conhecer a real necessidade da área a ser atuada a partir dos dados obtidos (XAVIER, 2008).

Diante do apresentado, apresenta-se a questão norteadora da pesquisa: como a análise de viabilidade pode contribuir para iniciar uma nova linha de transporte universitário da cidade de Toledo para Marechal Cândido Rondon-PR, no período matutino, em uma empresa de transporte universitário localizada no município de Toledo?

A pesquisa tem por objetivo analisar a viabilidade econômico-financeira de um projeto de abertura de uma nova linha de transporte universitário do município de Toledo para Marechal Cândido Rondon-PR.

Os objetivos específicos se concentram em: a) elaborar um plano de negócios; b) projetar o fluxo de caixa e c) verificar o retorno sobre o investimento.

O presente artigo está estruturado, além desta introdução, em mais quatro seções: na segunda, apresenta-se a fundamentação teórica a respeito do conceito de viabilidade e custo e da característica dos serviços; na terceira, descrevem-se os procedimentos metodológicos empregados para o desenvolvimento da pesquisa; na quarta, apresenta-se a análise dos resultados encontrados e, na quinta, expõem-se as conclusões e as considerações finais do estudo e sugestões para pesquisas futuras.

\section{Fundamentação Teórica}

\section{Serviço de Transporte de Passageiros}

Serviços são atos, processos e atuações oferecidos ou coproduzidos por uma entidade ou pessoa, para outra entidade ou pessoa (ZEITHAML; BITNER; GREMLER, 2014). A principal característica do serviço é a intangibilidade, dado que os serviços são execuções, ações e não objetos, não podem ser vistos, sentidos e nem tocados como um bem tangível.

O transporte de passageiros em regime de fretamento surgiu como uma modalidade alternativa para o transporte público, que não supre toda a demanda. Caracteriza-se como um serviço de transporte coletivo, que oferece um serviço privado e personalizável para transportar pessoas que possuem origem ou destinos em comum, tais como funcionários de uma empresa, turistas ou universitários (CNT, 2017). 
O transporte de passageiros por fretamento realiza a locomoção dos passageiros em três níveis: interestadual, internacional e intermunicipal. O transporte municipal é realizado entre dois bairros ou em um bairro e um distrito, no mesmo município. O transporte intermunicipal ocorre entre dois municípios do mesmo estado e, por fim, o transporte interestadual é executado entre dois municípios de estados diferentes (DER, 2016).

O fretamento é uma forma de transporte que vem crescendo e demonstrando alto potencial de expansão, tal qual é ampliado pela urbanização, pelo aumento da população e sua expectativa de vida, pela movimentação turística e universitária e pelas transformações econômicas e sociais que ocorrem no país (CNT, 2017).

Entretanto, mesmo sendo considerado como o principal modo de transporte de pessoas, o transporte rodoviário recebe uma infraestrutura com qualidade abaixa do esperado e insuficiente, prejudicando diretamente na eficiência desse serviço, que é afetado de forma negativa devido à qualidade oferecida pelas rodovias (CNT, 2017).

\section{Análise de Viabilidade}

A análise de viabilidade é considerada como um agregado de técnicas que permitem a comparação dos resultados de tomada de decisões e apresenta diferentes alternativas cientificas. Esta análise pode ser utilizada para escolher entre dois ou mais investimentos, como também para avaliar a possibilidade de implementar um novo empreendimento (VERAS, 2001). Surgiu com o objetivo de analisar as opções de investimentos e era considerada, na década de 1930, como uma engenharia econômica e, posteriormente, firmou-se como uma área de estudo de viabilidade (ANTONIK, 2001).

Um bom negócio é fruto da identificação de uma oportunidade e seu posterior estudo de viabilidade, a fim de tomar uma decisão satisfatória que proporcione avanços na empresa (DOLABELA, 1999). Levantar dados de possíveis ganhos e perdas e projetar qual será o retorno desse investimento são tarefas desafiadoras para o empreendedor (DAL ZOT, 2008).

Uma das técnicas utilizadas para analisar a viabilidade de um projeto é o plano de negócios, ferramenta utilizada para traçar um molde do mercado. É por meio deste que o empreendedor pode obter informações detalhadas que contribuirão para analisar a praticabilidade do seu negócio (SEBRAE, 2019). Para Hisrich e Peters (2004), o plano de negócio é utilizado para descrever todos os elementos externos e internos que podem influenciar o início de um novo empreendimento.

Salim et al. (2005) considera o plano de negócios como um documento que apresenta as características do empreendimento, as formas de operação, as estratégias do negócio, as metas a serem atingidas, as projeções e os resultados financeiros.

A falta de informações e planejamento de projetos, que são exigidos pelas entidades financiadoras, definem as maiores dificuldades das empresas para obter aprovação de créditos (AOKI; BADALOTTI, 2014).

\section{Payback}

O payback é uma técnica utilizada para calcular o tempo necessário para a empresa receber o retorno sobre o investimento inicial realizado no seu empreendimento. É uma ferramenta simples e, se o período do payback estiver dentro do previsto pelo empreendedor, a viabilidade será definida como positiva (DEGEN, 1989).

Essas informações são importantes por apresentarem ao investidor qual o risco de acordo com o tempo, ou seja, irá demonstrar quanto tempo levará para ele recuperar o capital investido (WEISE, 2013).

Dessa forma, essa técnica consiste em informar qual o tempo necessário para que o investimento cubra os seus gastos iniciais, em que a empresa precisará de um determinado tempo para recuperar o que foi investido e, apenas depois desse período, que ele apresentará um retorno real (SENAC, 2004).

Segundo Kuhnen e Bauer (1996), a melhor alternativa de investimento é sempre aquela que tem o menor período de retorno sobre o investimento. 


\section{Valor Presente Líquido (VPL)}

Segundo Gitman (1997), o valor presente líquido (VPL) pode ser adquirido por meio da diferença entre o valor presente nas entradas e saídas de caixa que acontecem durante determinado período de vida de um projeto deduzido de uma taxa de desconto do mercado.

O VPL é uma ferramenta confiável para analisar o investimento por considerar os fluxos de caixas estimáveis e o custo de oportunidade de capital, sendo que ele reconhece o valor do dinheiro no tempo (BREALEY; MYERS; ALLEN, 2013).

Esse método considera o valor do dinheiro no tempo e está sujeito unicamente aos fluxos de caixa do projeto e do custo de oportunidade do capital (BRUNI; FAMÁ, 2003).

Se o valor do VPL for positivo, significa que o projeto está gerando mais retorno do que o necessário para quitar suas dívidas com terceiros e fornecer resultados para seus investidores. Porém, se o mesmo for negativo, a empresa não estará gerando retorno e perderá valor (BRIGHAM; GAPENSKI; EHRHARDT, 2001).

\section{Taxa Interna de Retorno (TIR)}

A taxa interna de retorno (TIR) de um investimento, de acordo com Brom e Balian (2007), é a taxa demandada de retorno que irá garantir a reposição de um investimento. Se for usada como taxa de desconto, resultará em um VPL igual a zero.

Segundo Oliveira (1982), a TIR é aquela que torna o valor dos lucros igual ao valor dos gastos realizados com o negócio, assim essa taxa caracteriza-se como a taxa de remuneração esperada para o capital investido. Caso a TIR de um projeto for superior ao seu custo de financiamento, o projeto trará retorno ao seu investidor e deverá ser aceito. Porém, se a taxa for menor do que o custo, o projeto deve ser rejeitado (STALLA, 2010).

\section{Retorno sobre o Investimento (ROI)}

Segundo Hoji (2001), o método de retorno sobre o investimento (ROI) é uma das técnicas mais utilizadas para analisar investimento, já que ela relaciona os investimentos realizados no projeto com o lucro anual gerado. $\mathrm{O}$ ROI apresenta o índice da rentabilidade que o empreendedor terá no investimento do projeto, indicando o percentual de rendimento financeiro que ele terá sobre o capital inicial investido (GITMAN, 1997).

Os índices apresentados por este método mostram qual será a rentabilidade do capital investido, ou seja, qual o retorno dos investimentos e qual o resultado econômico da empresa (MATARAZZO, 2007).

\section{Taxa Mínima de Atratividade (TMA)}

A taxa mínima de atratividade (TMA) é utilizada como método financeiro para avaliar a taxa de juros referente à maior rentabilidade que pode ser obtida por meio das aplicações correntes e de pouco risco. Para uma proposta de negócio ser realmente atrativa ela precisa ser superior a esta taxa.

Comparar essas alternativas requer uma fixação da TMA, referente ao custo de oportunidade do investido, que pode ser representada pela taxa de aplicação básica no mercado (PUCCINI, 2004).

\section{Ponto de Equilíbrio}

O ponto de equilíbrio é uma importante ferramenta utilizada para analisar a quantidade de unidades ou o valor que deve ser obtido para alcançar um equilíbrio no resultado, para que ele gere um resultado zero, ou seja, sem lucro ou prejuízo. Ele representa o valor necessário para que a empresa iguale seus gastos totais e pode ser determinado, tanto em quantidade, quanto em receita total (JIAMBALVO, 2002). 


\section{Procedimentos metodológicos}

Para analisar a viabilidade econômica de um novo projeto de uma empresa de transporte universitário e turismo, localizada na cidade de Toledo, no estado do Paraná, optou-se por uma abordagem quantitativa do problema, que retrata, num primeiro momento, "a intenção de garantir a precisão dos resultados, evitar distorções de análise e interpretação, possibilitando, consequentemente, uma margem de segurança quanto às inferências" (RICHARDSON, 1999, p. 70).

Quanto aos objetivos, esta pesquisa classifica-se como exploratória e descritiva. "A investigação exploratória é realizada em área que há pouco conhecimento acumulado e sistematizado" (VERGARA, 2013, p. 41) e a pesquisa exploratória se objetiva em proporcionar uma visão geral acerca de determinado fato (GIL, 1999).

A pesquisa descritiva exibe a descrição das características de alguma população ou fenômeno ou a afirmação de relações entre as variáveis (GIL, 1999). Dessa forma, “a pesquisa descritiva tem como foco observar os fatos, registrá-los, analisá-los, classificá-los e intepretá-los, sendo que, o pesquisador não interfere neles” (ANDRADE, 2002, p. 81).

Quanto aos meios de investigação utilizados, a pesquisa é documental. Segundo Silva e Grigolo (2002) afirmam que a pesquisa documental visa selecionar, tratar e interpretar informações brutas, na busca de extrair algum sentido e introduzir valor para futuramente contribuir com a comunidade cientifica. Nesse tipo de pesquisa, os dados são classificados em dois tipos, os de fonte primária e os de fonte secundária. O presente trabalho utiliza de dados secundários que, segundo Kotler (1998), são obtidos por meio de informações já colhidas por outro alguém para algum propósito.

O critério de escolha da empresa foi o de acessibilidade, proporcionado pela organização aos pesquisadores. Os dados foram coletados por meio de documentos já existentes, tais como: relatórios contábeis da empresa e orçamentos fornecidos por terceiros.

Para realizar a análise de viabilidade do projeto empregaram-se as técnicas de análise de investimento, descritos no referencial teórico, acompanhadas das seguintes fórmulas:

Payback $=\frac{\text { Investimento Inicial }}{\text { Entrada de caixa no período }}$

$\boldsymbol{V P} \boldsymbol{L}=\sum_{i=0}^{n} \frac{F C_{t}}{(1+i)^{t}}$, onde:

$F C_{t}$ : Fluxo de Caixa no período $\mathrm{t}$

$i$ : taxa de desconto

$t$ : período

$\boldsymbol{T I R}=(V P L=0)=\sum_{i=0}^{n} \frac{F C_{t}}{(1+T I R)^{t}}$, onde:

$F C_{t}$ : Fluxo de caixa no período $t$

$V P L=0$

$t$ : período

$\boldsymbol{R O I}=\frac{\text { lucro liquido do período }}{\text { investimento } \text { inicial }} \times 100$

Ponto de Equilíbrio $=\frac{\text { Custo Fixo }}{\text { Receita-Custo Variável }} \times 100$ 


\section{Apresentação e análise dos resultados}

Esta seção apresenta os dados divididos em três blocos: no primeiro, o perfil do empreendimento, no segundo, os dados referentes ao capital investido e o faturamento e, no terceiro, os resultados obtidos por meio da análise de viabilidade.

\section{O Empreendimento}

A análise de viabilidade relacionou-se à abertura de um novo empreendimento em uma empresa de transporte universitário e de turismo, localizada no estado do Paraná, no município de Toledo. A empresa já oferece serviços de transporte turístico e de transporte universitário para o município de Marechal Cândido Rondon, no estado do Paraná, no período noturno e pretende dar início a um novo empreendimento de transporte universitário para o município, no período matutino.

\section{Capital Investido e Faturamento}

Para iniciar as análises, foram coletados alguns dados referentes ao faturamento da empresa e o capital que deveria ser investido para a efetivação do novo empreendimento.

Tabela 1: Faturamento e investimentos

\begin{tabular}{l|c|r|r}
\hline & Quantidade & Valor & \multicolumn{1}{l}{ Total } \\
\hline Faturamento & 36 Passageiros & $\mathrm{R} \$ 370,00$ & $\mathrm{R} \$ 13.320,00$ \\
\hline Custos Variáveis & - & - & $\mathrm{R} \$ 199,80$ \\
\hline Custos Fixos & - & - & $\mathrm{R} \$ 5.130,00$ \\
\hline Resultado Operacional & - & - & $\mathrm{R} \$ 7.990,20$ \\
\hline Financiamento & - & - & $\mathrm{R} \$ 90.000,0000000$ \\
\hline Capital Próprio & - & - & \\
\hline
\end{tabular}

Fonte: Dados da pesquisa (2019).

Percebe-se, por meio dos dados da Tabela 1 que, o investimento inicial da empresa para o novo empreendimento, seria de $\mathrm{R} \$ 190.000,00$ (cento e noventa mil reais), sendo $\mathrm{R} \$ 100.000,00$ (cem mil reais) frutos de um financiamento e o valor restante retirado do capital próprio da empresa. Como a mesma já possui uma estrutura física estabelecida, será necessário apenas realizar a compra do novo veículo que seria, a partir daquele momento, utilizado inicialmente para o transporte dos passageiros do período matutino.

Como o veículo teria capacidade para transportar 36 passageiros e se pretenderia cobrar um valor mensal de $\mathrm{R} \$$ 370,00 (trezentos e setenta mil reais), ter-se-ia um faturamento estimado de $\mathrm{R} \$ 13.320,00$ (treze mil trezentos e vinte reais). Ainda, de acordo com a Tabela 1 , teríamos os custos fixos e as variáveis que somariam a quantia de $\mathrm{R} \$$ 5.329,80 (cinco mil, trezentos e vinte e nove reais e oitenta centavos). Dentro deste valor já estão sendo considerados os encargos e as previsões trabalhistas, as depreciações e as outras despesas operacionais. Por fim, após considerarmos todos esses valores, obteve-se um resultado operacional de R\$7.990, 20 (sete mil novecentos e noventa reais e vinte centavos). 


\section{Avaliação do Empreendimento}

Nesta etapa, apresentam-se as análises de viabilidade do novo negócio.

Tabela 2: Rentabilidade e lucratividade

\begin{tabular}{l|c|l|c}
\hline \multicolumn{2}{l|}{ Rentabilidade } & Lucratividade \\
\hline Média Mensal & $2,75 \%$ & Média Mensal & $42,88 \%$ \\
\hline Período de 60 meses & $4.783,23 \%$ & & \\
\hline
\end{tabular}

Fonte: Dados da pesquisa (2019).

De acordo com os dados obtidos anteriormente e de acordo com a Tabela 2, observou-se que a rentabilidade média mensal desse novo empreendimento seria de 2,75\% e, no período de 60 meses, ter-se-ia uma rentabilidade de 4.783,23\%. Já, em relação à lucratividade estima-se uma média mensal de 42,88\%.

Tabela 3: Prazo de retorno do investimento

\begin{tabular}{l|c}
\hline Prazo de Retorno do Investimento \\
\hline Resultado Operacional & 34 Meses \\
\hline Resultado Final & 38 Meses \\
\hline
\end{tabular}

Fonte: Dados da pesquisa (2019).

Conforme a Tabela 3, caso seja realizado o investimento, estima-se que o prazo de retorno do valor, levando em consideração o seu resultado operacional, seria de 34 meses, enquanto isso o resultado final levaria 38 meses para ser atingido.

Tabela 4: Taxas de retorno

\begin{tabular}{l|c}
\hline \multicolumn{2}{l}{ Taxa de Retorno } \\
\hline TMA - Taxa Mínima de Atratividade & $11,35 \%$ \\
\hline TIR - Taxa Interna de Retorno & $19,37 \%$ \\
\hline VPL - Valor Presente Líquido & $35.484,28$ \\
\hline
\end{tabular}

Fonte: Dados da pesquisa (2019).

Ao analisar a Tabela 4, é possível observar que a empresa apresentaria uma TMA de 11,35\%, sendo superior a taxa de juros referente a maior rentabilidade que pode ser obtida por meio das aplicações correntes e de pouco risco. A taxa interna de retorno seria de 19,37\%, sendo superior ao investimento inicial realizado e, por último, o valor presente líquido (VPL) da empresa seria de $\mathrm{R} \$ 35.484,28$ (trinta e cinco mil, quatrocentos e oitenta e quatro reais e vinte e oito centavos), ou seja, significa que o projeto estaria gerando mais retorno do que o necessário para quitar suas dívidas. 
Tabela 5: Ponto de equilíbrio

\begin{tabular}{l|c}
\hline \multicolumn{3}{c}{ Ponto de Equilíbrio - Operacional } \\
\hline Mensal & $\mathrm{R} \$ 5.208,12$ \\
\hline Diário & $\mathrm{R} \$ 208,32$ \\
\hline
\end{tabular}

Fonte: Dados da pesquisa (2019).

Segundo a Tabela 5, na qual se apresenta o ponto de equilíbrio da empresa, a média mensal necessária para igualar os gastos totais, ou seja, para não gerar prejuízo ou lucro para a empresa, seria de R $\$ 5.208,12$ (cinco mil, duzentos e oito reais e doze centavos), já a média diária seria de $\mathrm{R} \$ 208,32$ (duzentos e oito reais e trinta e dois centavos).

\section{Considerações finais}

Este estudo, o qual objetivou analisar a viabilidade da implementação de um novo empreendimento em uma empresa do ramo de transporte universitário e turismo, localizado na cidade de Toledo, no Oeste do Paraná, o qual já oferece serviços de transporte turístico universitário para o município de Marechal Cândido Rondon, no período noturno e pretende dar início a um novo empreendimento de transporte universitário para o mesmo município, no período matutino.

O ramo de transportes em especial de passageiros, faz uso de insumos derivados de petróleo, cujos preços dependem das cotações dessa matéria-prima no mercado internacional. Desse modo, as constantes alterações, no mercado brasileiro, dos preços dos produtos derivados do petróleo refletem sobremaneira nos custos das empresas de transportes. Ainda, afetam os resultados econômicos do setor e as suas lucratividades.

Nesse contexto, por meio deste estudo de viabilidade, foi possível observar a real importância de se analisar a viabilidade de um novo empreendimento antes de executá-lo. Assim, possibilitou-se reduzir os riscos associados às incertezas, nortear o empresário quanto às expectativas e ter uma noção de como o projeto iria funcionar.

Foram coletados alguns dados, como o faturamento mensal, os custos variáveis e fixos, o resultado operacional, entre outros valores da empresa, fazendo com que fosse possível a aplicação dos indicadores de análise da viabilidade.

Pelos indicadores, constatou-se que o valor presente líquido (VPL) seria de $\mathrm{R} \$ 35.484,28$ (trinta e cinco mil, quatrocentos e oitenta e quatro reais e vinte e oito centavos), por meio do qual se torna possível afirmar que o projeto estaria gerando mais retorno do que o necessário para quitar suas dívidas e investimentos. A lucratividade mensal foi prevista em 42,88\%, com uma rentabilidade mensal de 2,75\%. Em relação à taxa interna de retorno (TIR) obteve-se um percentual de 19,37\%, superior a taxa mínima de atratividade (TMA), que seria de 11,35\%.

Estima-se que o prazo de retorno do investimento é de 34 meses. No entanto, quando se trata do seu resultado operacional, para se obter um retorno sobre o resultado final desse novo empreendimento, seria necessário um prazo de 38 meses.

As análises dos indicadores estudados demontraram que o projeto gera retornos suficientes que possitbilitariam ao empreendedor quitar suas dividas. Por outro lado, a lucratividade mensal e a taxa mínima de atratividade (TMA), também proporcionariam rentabilidade ao negócio.

Por fim, a partir dos resultados obtidos pelos indicadores de viabilidade estudados neste estudo, conclui-se que o novo emprendimento é viável e poderia ser realizado pelo gestor da empresa.

Como limitação, tem-se que este estudo não pode ser generalizado para outras empresas, pois foi aplicado em uma específica, sendo necessária a replicação para posteriores generalizações. 
Análise de viabilidade: implementação de um novo empreendimento em uma empresa de transporte universitário e turismo de Toledo

\section{Referências}

ANDRADE, Maria Margarida de. Como preparar trabalhos para cursos de pós-graduação: noções práticas. 5. Ed. São Paulo: Atlas, 2002.

ANTONIK, L. R. Análise de projetos de investimentos: uma abordagem teórico-prática. 115 f. 2001. Dissertação (Mestrado Executivo) - Escola Brasileira de Administração Pública - Fundação Getúlio Vargas, Curitiba, 2001.

AOKI, V. C. G.; BADALOTTI, R. M. Dificuldades e perspectivas no acesso de micro e pequenas empresas a linhas de crédito públicas: o caso de Chapecó. Revista de Administração Pública, Rio de Janeiro, v. 48, n. 05, p. 1305-1327, jan./out. 2014.

BRASIL. Decreto $\mathbf{n}^{\mathbf{0}} \mathbf{8 . 0 8 3}$, de 26 de agosto de 2013. Altera o Decreto ${ }^{\circ} 2.521$, de 20 de março de 1998, que dispõe sobre a exploração, mediante permissão e autorização, de serviços de transporte rodoviário interestadual e internacional de passageiros e dá outras providências. Disponível em: <www.planalto.gov.br/ccivil_03/_Ato2011-2014/2013/Decreto/D8083.htm>. Acesso em: 23 de mar. de 2019.

BREALEY, Richard A.; MYERS, Stewart C.; ALLEN, Franklin. Princípios de finanças corporativas. 10. ed. Porto Alegre: AMGH, 2013.

BRIGHAM, E.; GAPENSKI, L.; EHRHARDT, M. C. Administração financeira: teoria e prática. São Paulo: Atlas, 2001.

BROM, L. G.; BALIAN, J. E. A. Análise de investimentos e capital de giro: conceitos e aplicações. São Paulo: Saraiva, 2007.

BRUNI, A. L.; FAMÁ, R. As decisões de investimento: com aplicações na HP 12C e excel. São Paulo: Atlas, 2003.

CNT (CONFEDERAÇÃO NACIONAL DO TRANSPORTE). Transporte Rodoviário de passageiros em regime de fretamento. Disponível em: http://cms.cnt.org.br/Imagens\%20CNT/PDFs\%20CNT/Estudos\%20CNT/2017\%20CNT\%20Transporte\%2 0Rodovi $\%$ C3\%A1 rio $\% 20 \mathrm{de} \% 20$ Passageiros $\% 20 \mathrm{em} \% 20$ Regime $\% 20 \mathrm{de} \% 20$ Fretamento $\% 20060317 \% 20(1)$.pdf. Acesso em: 23 de mar. de 2019.

CONFEDERAÇÃO NACIONAL DO TRANSPORTE (CNT). Transporte rodoviário: desempenho do setor, infraestrutura e investimentos. Disponível em: http://cms.cnt.org.br/Imagens \%20CNT/PDFs $\% 20 \mathrm{CNT} /$ Estudos $\% 20 \mathrm{CNT} /$ estudo_transporte_rodoviario_inf raestrutura.pdf. Acesso em: 23 de março de 2019.

DAL ZOT, E. Análise de investimento: estudo para abertura de filial de rede de educação profissional. 54 f. 2008. Trabalho de Conclusão Curso (Graduação em Administração) - Escola de Administração - Universidade Federal do Rio Grande do Sul, Porto Alegre, 2008.

DEGEN, R. J.; MELLO, A. A. A. O empreendedor: fundamentos da iniciativa empresarial. São Paulo: McGraw-Hill, 1989.

DER (DEPARTAMENDO DE RODAGEM DE ESTRADAS). Manual do Transportador. Disponível em: http://www.der.pr.gov.br/arquivos/File/Manual doTransportador2816.pdf. Acesso em: 23 de março de 2019.

DOLABELA, Fernando. O segredo de Luísa. São Paulo: Cultura Editores Associados, 1999.

GIL, Antônio Carlos. Como elaborar projetos de pesquisa. São Paulo: Atlas, 2010.

GIL, Antônio Carlos. Métodos e técnicas de pesquisa social. 5. Ed. São Paulo: Atlas, 1999.

GITMAN, L. J. Princípios da administração financeira. São Paulo: Habra, 1997.

HISRICH, Robert D.: PETERS, Michael P. Empreendedorismo. Porto Alegre: Bookmann, 2005.

HOJI, M. Administração financeira: uma abordagem prática. $3^{a}$ edição. São Paulo: Atlas, 2001.

JIAMBALVO, JAMES. Contabilidade gerencial, tradutor: Tatiana Carneiro Quírico, ed. LTC, Rio de Janeiro, 2000. 
KOTLER, P. Administração de marketing: análise, planejamento, implementação e controle. São Paulo: Atlas, 1998.

KUHNEN, O. L; BAUER, U. R. Matemática financeira aplicada e análise de investimentos. $6^{a}$ edição. São Paulo: Atlas, 1996.

LONGENECKER, J. G.; MOORE, C. W.; PETTY, J. W. (1997). Administração de pequenas empresas: ênfase na gerência empresarial. São Paulo: Makron Books.

MATARAZZO, D. Análise financeira de balanços. 6a edição. São Paulo: Atlas, 2007.

NERI, A. S. C. A influência da qualidade percebida, do valor percebido e do custo de mudança sobre a lealdade dos usuários do serviço de saúde suplementar. 2013. 153 f. Dissertação (Mestrado em Administração) - Programa de Mestrado Profissional em Administração Gestão em Sistemas de Saúde, Universidade Nove de Julho, São Paulo, 2015.

OLIVEIRA, J. A. N. Engenharia econômica: uma abordagem as decisões de investimento. São Paulo: McGraw-Hill, 1982.

PORTER, M. E. Competição: estratégias competitivas essenciais. 9. ed. Rio de Janeiro: Campus, 1999.

PUCCINI, A. L. (2004). Matemática financeira: objetiva e aplicada. 7. ed. São Paulo: Saraiva.

RICHARDSON, R. J. Pesquisa social: métodos e técnicas. São Paulo: Atlas, 1999.

SALIM, César Simões. et al. Construindo planos de negócios. 3. ed. rev. e atual. Rio de Janeiro: Elsevier, 2005.

SEBRAE (SERVIÇO BRASILEIRO DE APOIO ÀS MICRO E PEQUENAS EMPRESAS), Tudo o que você precisa saber para criar o seu plano de negócio. 2019. Disponível em: http://www.sebrae.com.br/sites/PortalSebrae/artigos/como-elaborar-um-plano-de-

negocio,37d2438af1c92410VgnVCM100000b272010aRCRD. Acesso em: 23 de março de 2019.

SEBRAE (SERVIÇO BRASILEIRO DE APOIO ÀS MICRO E PEQUENAS EMPRESAS), Anuário do trabalho na micro e pequena empresa: 2008. Brasília: DIEESE, 2008.

SENAC (SERVIÇO NACIONAL DE APRENDIZAGEM COMERCIAL). Básico de Contabilidade e Finanças. Rio de Janeiro: SENAC, 2004.

SILVA, Marise Borba de; GRIGOLO, Tânia Maris. Metodologia para iniciação cientifica à prática da pesquisa e da extensão II. Caderno Pedagógico. Florianópolis: Udesc, 2002.

STALLA, R. Fixed-Income Securities \& Equity Analysis: Comprehensive Study Guide for the CFA Exam. Westlake/Ohio: Argentum Inc., 2010.

VERAS, L. L. Matemática financeira: uso de calculadoras financeiras, aplicações ao mercado financeiro, introdução à engenharia econômica, 300 exercícios resolvidos e propostos com respostas. 4. ed. São Paulo: Atlas, 2001.

VERGARA, Sylvia Constant. Projetos e relatórios de pesquisa em administração. 14. Ed. São Paulo: Atlas, 2013.

WEISE, A. D. Engenharia econômica: polígrafo disciplina engenharia econômica. Santa Maria: Pós-graduação em Engenharia Produção, 2013.

XAVIER, Carlos Magno da Silva e outros. Metodologia de gerenciamento de projetos no terceiro setor. Rio de Janeiro: Brasport, 2008.

ZEITHAML, V. A.; BITNER, M. J.; GREMLER, D. D. Marketing de serviços: a empresa com foco no cliente. 6. ed. Porto Alegre: Editora Bookman, 2014. 